\title{
THE TRANSPLANTATION OF EYES TO GENETICALLY EYELESS SALAMANDERS: VISUAL PROJECTIONS AND SOMATOSENSORY INTERACTIONS ${ }^{1}$
}

\author{
WILLIAM A. HARRIS
}

Department of Biology, University of California San Diego, La Jolla, California 92093

Received September 11, 1981; Revised November 4, 1981; Accepted November 6, 1981

\begin{abstract}
Eyes were transplanted from normal axolotls to eyeless mutants, and several anatomical and physiological observations were made on the central visual centers in these animals. Some central projections were bilateral to the optic centers of the thalamus and midbrain, some traveled ipsilaterally to the same centers, and the rest grew down the spinal cord. This is similar to what has been found in eyes transplanted to normal hosts. The type of projection made in eyeless hosts correlated with the site of nerve entry into the CNS as in control hosts. Thus, the transplanted projection did not appear to be influenced by the host's optic nerves and tracts or lack of them. In spite of the transplanted optic fibers' taking abnormal paths, they made normally organized topographic maps on the host tecta. The visual and somatosensory topographic projections to the tectum were found to be in near perfect register normally, but in eyeless mutants to which rotated eyes had been transplanted, they were not. Acetylcholinesterase activity, found in the primary optic neuropil in normal animals, was greatly diminished in eyeless mutants, yet normal in mutants with grafted eyes. Finally, transplantation of an eye to an eyeless mutant corrected the abnormally dark pigmentation caused by eyelessness but only in those cases of bilateral central innervation.
\end{abstract}

The eyeless axolotl is a recessive mutant which arose spontaneously in the laboratory of Dr. R. R. Humphrey (1969). As a result of a defect expressed early in organogenesis, the optic vesicle in this mutant never emerges from the diencephalic wall (Van Deusen, 1973; Brun, 1978, 1980; Epp, 1978; Ulshafer and Hibbard, 1979). The eyeless mutation also affects other parts of the central nervous system (CNS). For example, it causes a hypothalamic dysfunction which leads to sterility (Humphrey, 1969; Van Deusen, 1973). It also causes a pigmentation defect and a reorganization of the dorsal midbrain (see below). If embryological transplantation of an eye to the eyeless mutant corrects these central changes, then one can be certain that they are due to deafferentation and not a direct action of the mutation on the CNS. When an

\footnotetext{
'This work was supported by National Institutes of Health Grant HI) 14490-01, by a Scholar's Award from the McKnight Foundation, and by a Basil O'Connor Grant from the March of Dimes. Additional funding came from the Academic Senate of the University of California, San Diego. Bobby Dolin and Terry Tokar raised the animals which were generously supplied by the Axolotl Colony at Indiana University. I also thank Jeff Hall, Betty Ferguson, Julia Cole, John Bixby, Nick Spitzer, Janet Lamborghini, Max Cowan, Ed Gruberg, and Emerson Hibbard for criticisms of the manuscript and Christy Harper for several of the illustrations.
}

eye is transplanted to an eyeless axolotl, transplanted retinal fibers occupy their normal position in the superficial tectal neuropil (Hibbard and Ornberg, 1976; Schwenk and Hibbard, 1977). Somatosensory input to the tectum, which is abnormally superficial in the mutant, is restricted to the normally deep neuropil (Gruberg and Harris, 1981). These findings argue that much of the tectal reorganization in the eyeless animal is indeed a consequence of retinal deafferentation and not a primary action of the mutation.

The transplantation of eyes to eyeless mutants is also useful in testing certain ideas about the development of neural connections. It has been proposed that normal morphogenetic relationships in the developing optic stalk, nerve, and tract are ultimately responsible for routing optic axons to their topographically correct central targets (Horder and Martin, 1978). However, axons are not required to follow normal paths, since axons of extra eyes transplanted to normally eyed animals grow to their proper targets by abnormal paths (Hibbard, 1959; Sharma, 1972; Constantine-Paton and Law, 1978; Harris, 1980). It is possible, though, that these abnormally growing fibers are able to find their targets only by contacting and then being guided by the terminals of normally routed axons from the host's eyes. The eyeless axolotl, 
since it never forms an eye, is thus an interesting host for such experiments, for an eye can be transplanted to such a position that an abnormal path to the tectum is ensured in a situation where there are no host optic fibers to follow.

In the tecta of many animal species, the somatosensory, auditory, or thermosensory maps are in register with the visual map. It is possible that a functional interaction of these modalities during development is necessary to produce a consistent map of the world in the tectum. In eyeless mouse mutants, however, the somatosensory tectal maps are essentially normal (Drager, 1977), which suggests that the maps arise independently. A much stronger test, however, of the possible functional interdependence of visual and somatosensory maps is to see whether a misalignment of the two maps is stable. In this paper, eyes are transplanted to eyeless axolotls in rotated orientations in order to create potential mismatches of the visual and somatosensory axes in the tectum.

\section{Materials and Methods}

Animals. The progeny of matings between axolotls heterozygous for the recessive autosomal mutation $e$ (for eyeless) and homozygous for $d$ (white) were generously supplied by the Axolotl Colony at Indiana University. 'I The eyeless mutation is kept in a genetic background of white because white accentuates the pigmentation defect. One-quarter of such embryos become eyeless in phenotype. Since homozygous eyeless mutants express their phenotype in the failure to form optic vesicles (Humphrey, 1969; Van Deusen, 1973), these embryos sometimes can be recognized by the absence of optic bulges as early as stage 23 (Bordzilovskaya and Dettlaff, 1979). Early larvae were fed freshly hatched brine shrimp daily. Older animals were fed a mixture of beef liver and Gaines Burgers. All animals were raised in glass bowls in $50 \%$ Holtfreter's solution (Rugh, 1962).

Transplantations. Eye transplantations were done from normal to suspected eyeless embryos between stages 23 and 30 (Bordzilovskaya and Dettlaff, 1979). This is before optic nerve fibers have been reported to grow into the stalk, stage 34 (Herrick, 1941), and before polarization of the retinal axes has been reported to be fixed, stage 36 (Stone, 1960). In most instances, eyes were transplanted to the same side of the host's head as they were in the donor, although occasional crossed transplantations were performed and recorded. No attempt was made to keep track of the orientation of the transplants and it is assumed that this was arbitrary. About 200 such operations were done; about 80 proved to be transplants from normal to eyeless animals. The other hosts were normal animals and this resulted in three-eyed axolotls. The operations were done under a dissecting microscope with fine forceps and a sharpened tungsten scalpel in a sterile agar dish. The operating medium was $100 \%$ Steinberg's solution (Rugh, 1962) containing twice the normal concentration of $\mathrm{Ca}^{2+}$ and $\mathrm{Mg}^{2+}$ to accelerate healing. Gentamicin $(0.005 \%)$, penicillin $(0.04 \%)$, and streptomycin $(0.04 \%)$ also were added.

The eyecup, together with the entire optic stalk, was removed from the donor. A wound was made in the host ectoderm, dorsal and posterior to the position of the host eye, or to a corresponding position in eyeless animals, because one aim of the study was to compare transplants to eyeless with transplants to normal embryos. A small chip of sterilized cover glass was used to hold the transplant in place during the 1st hr of healing. Approximately $24 \mathrm{hr}$ later, the embryos were transferred to $50 \%$ Holtfreter's solution. About 40 eyeless mutants with successful transplants survived for at least 3 months. Twenty three of these were used for this study.

Anatomy. Anterograde axonal transport from the retina to the brain was studied by injecting tritiated proline (10 $\mu \mathrm{Ci}$ in $1 \mu \mathrm{l}$ of saline) into the eye. In some animals, a micropipette was used to deliver $1 \mu$ of a "cocktail" containing $30 \%$ horseradish peroxidase (HRP) and $5 \%$ lysolecithin into the eye (see Frank et al., 1980). Two to 3 days after an injection, the animal was anesthetized and perfused through the heart with $2 \%$ formaldehyde and $2 \%$ glutaraldehyde in $0.1 \mathrm{M}$ phosphate buffer at $\mathrm{pH}$ 7.3. After fixation for several hours at $4^{\circ} \mathrm{C}$, the brains were dissected out and placed in cold phosphate buffer for 2 to $24 \mathrm{hr}$. Brains to be sectioned were embedded in a $0.5 \%$ gelatin, $30 \%$ albumin mixture hardened with glutaraldehyde and cut at $40 \mu \mathrm{m}$ on a Vibratome. For autoradiographic studies, sections were mounted on subbed slides, dipped in Ilford emulsion, and developed after 2 weeks. The distribution of HRP was revealed by reacting sections with the diaminobenzidine procedure (Malmgren and Olsson, 1978). Some unsectioned brains also were reacted for HRP (Fujisawa et al., 1981).

For cholinesterase studies, brains were fixed and sectioned as above and then stained according to the method of Karnovsky and Roots (1964) using acetylthiocholine iodide. Specificity of the reaction was not checked carefully because of Gruberg and Greenhouse's (1973) confirmation of specificity in the closely related Tiger salamander. However, $10 \mathrm{~mm}$ BW284C51 (a specific inhibitor of acetylcholinesterase) completely inhibited the staining in axolotls.

Electrophysiology. Animals from 3 to 9 months old were anesthetized in a 1:5000 solution of MS-222 (ethyl $m$-aminobenzoate methanesulfonic acid, Aldrich) in $100 \%$ Steinberg's solution with $1 \%$ dextrose and were maintained on light anesthesia throughout the preparative surgery and physiological recording. An animal was placed in a Petri dish with Sylgard inclined on one side. A single insect pin was used to fix the head to the Sylgard. The solution level was adjusted so that the head of the animal was out of the solution, while the body and gills remained submerged.

The tectum was exposed by peeling back the overlying skin and then opening the skull and dura with forceps. A Polaroid photograph then was made of the tectal surface, and the site of each penetration was marked on the photograph to record the electrode placement. The electrode penetrations were made roughly perpendicular to the tectal surface. The electrodes used were metal-filled glass pipettes with platinum-blacked tips (Lettvin et al., 1959) and recorded either single or multiple unit responses. The signal from the electrode was amplified $x$ 1000 , displayed on an oscilloscope, and fed into an audio monitor. 
Visual receptive fields were mapped by centering the animal over a polar coordinate grid such that the rear of its head was directly over the origin. The optimal receptive field positions for each cell or group of cells were determined by positioning a $2-\mathrm{cm}$ black target (representing about $8^{\circ}$ at $15 \mathrm{~cm}$ ) over various parts of the animal's visual field and judging the maximal response. Inferior-superior coordinates were estimated with the aid of another polar grid which was orthogonal to the long axis of the animal. To map somatosensory fields in the deeper tectal neuropil, the eye projecting to that tectum first was occluded with a piece of wet black paper; then the animal was stroked lightly with a short human hair attached to a glass rod. Since the animal was positioned over the polar grid, the optimal receptive field area for tactile stimulation at each electrode placement could be found and compared directly to the visual fields. Besides noting the polar coordinate angle for the somatosensory fields, the parts of the body comprising these fields also were noted. In this way, an "Ambystomunculus" was constructed which directly related the angular coordinates to the animal's body.

\section{Results}

The retinal projections in normal axolotls are very similar to those described for the Tiger salamander (Herrick, 1948; Jakway and Riss, 1972). The optic nerve enters the brain at the chiasm which is located at the ventral midline of the hypothalamus. Most fibers project contralaterally, giving rise to terminals in the rostral thalamus, the nucleus of Bellonci, the pretectum, the dorsal tectum, and the basal optic root. There are substantial, but less dense, ipsilateral projections to the same diencephalic centers and very weak projections to the ipsilateral tectum (limited to the rostral border of the visual neuropil) and the basal optic root. The tectal visual neuropil in normal adult axolotls extends about $200 \mu \mathrm{m}$ from the pial surface, and below this retinal input is a neuropil layer of about 100 to $150 \mu \mathrm{m}$ which contains serotonergic terminals and is somatosensory in function (Gruberg and Solish, 1978; Gruberg and Harris, 1981). Below this, there are about $100 \mu \mathrm{m}$ of other functionally unidentified deep neuropil layers and then a cellular layer about $400 \mu \mathrm{m}$ thick. This simplified account of the normal visual projections and tectal anatomy may be contrasted to the results obtained from transplanting eyes to eyeless mutants. A single eyeless host often was used for many types of experiment. Table I shows which animals were used for which studies.

The transplanted projection. Optic nerves from eyes transplanted to eyeless axolotls entered the central nervous system in 21 of 23 cases. 'This was shown by neuroanatomical tracing with $\left[{ }^{3} \mathrm{H}\right]$ proline or $\mathrm{HRP}$ or by electrophysiological recording. As in grafts to normal animals, the transplanted optic nerves entered the host brains at various points, often at ectopic sites in the diencephalon, mesencephalon, or even metencephalon. These entry points are shown diagrammatically in Figure $1 A$, (see also Figs. 2 and 3 ); they did not correspond to the central attachment sites of any of the cranial nerves. The only difference between these results and those previously reported for grafts to normal hosts (Harris,
TABLE I

\section{Summary of results}

The numbers listed under "Animal" are simply identification numbers. "EP" stands for entry point and the pairs of numbers listed in this column are, respectively, the anterior-posterior and dorsal-ventral coordinates (see Fig. 1A). "Dest." means destination; under it, B stands for bilateral, I for ipsilateral, and SC for spinal cord. "Maps" means tectal physiology was done: $\mathrm{V}$, visual; $\mathrm{S}$, somatosensory; $\mathrm{n}$ and $\mathrm{r}$ stand for normal and rotated. "AChE" means acetylcholinesterase histochemistry was examined and $\mathrm{N}$ indicates that it was normal. " 5 -HT" stands for serotonin histochemistry, the results of which are reported in Gruberg and Harris (1981). "Pig." means pigmentation was checked; L and D stand for light and dark.

\begin{tabular}{|c|c|c|c|c|c|c|}
\hline Animal & EP & Dest. & Maps & $\mathrm{AChE}$ & $5-\overline{H T}$ & Pig. \\
\hline 164 & 36,30 & I & $\mathrm{Vn}$ & & & $\mathbf{L}$ \\
\hline 186 & & B & $V_{n}$ & & $\mathbf{N}$ & $\mathrm{L}$ \\
\hline 187 & & I & $\mathrm{Vr}$ & & $\mathrm{N}$ & $\mathrm{D}$ \\
\hline 195 & 31,61 & I & $\mathrm{Vr}, \mathrm{Sn}$ & & & \\
\hline 197 & 39,58 & B & $\mathrm{Vn}, \mathrm{Sn}$ & & & \\
\hline 198 & 41,54 & I & $\mathrm{Vr}, \mathrm{Sn}$ & & & \\
\hline 201 & $207, \mathrm{I} 1$ & $\mathrm{SC}$ & & & & $\mathrm{L}$ \\
\hline 242 & 43,50 & I & Vr, Sn & & & $\mathrm{D}$ \\
\hline 251 & 23,60 & B & $\mathrm{Vr}, \mathrm{Sn}$ & $\mathbf{N}$ & & $\mathrm{L}$ \\
\hline 256 & 17,25 & B & $\mathrm{Vr}, \mathrm{Sn}$ & & & $\mathbf{L}$ \\
\hline 257 & 44,69 & I & $\mathrm{Vr}, \mathrm{Sn}$ & & & D \\
\hline 258 & 107,51 & $\mathrm{SC}$ & & & & D \\
\hline 259 & 42,38 & I & & & & $\mathbf{L}$ \\
\hline 260 & 29,36 & $\mathbf{B}$ & & & & I. \\
\hline 261 & 111,42 & SC & & & & $\mathrm{D}$ \\
\hline 262 & 35,48 & I & & & & $\mathrm{D}$ \\
\hline 263 & 27,54 & B & $\mathrm{Vn}, \mathrm{Sn}$ & & & L \\
\hline 264 & 49,58 & I & $\mathrm{Vr}, \mathrm{Sn}$ & & & $\mathrm{D}$ \\
\hline 271 & 27,43 & B & & $\mathrm{N}$ & & $\mathrm{L}$ \\
\hline 272 & 30,65 & I & & & & $\mathrm{L}$ \\
\hline 274 & 48,10 & I & $\mathrm{Vr}$ & & & $\mathrm{D}$ \\
\hline
\end{tabular}

1980) is that, in the latter, an occasional transplanted optic nerve joined the host optic nerve and thereby entered the brain normally at the chiasm.

Within the central nervous system, three distinct projection patterns were found: (1) a bilateral projection to the visual centers in the thalamus and midbrain $(n=7)$, (2) an ipsilateral projection to the same visual centers ( $n$ $=11$ ), and (3) an ipsilateral projection to the spinal cord $(n=3)$. Examples of these projections are shown in Figures 2, 3, and 4. In all bilateral projections, optic fibers from the transplanted eyes crossed to the contralateral side of the brain at or very near the site at which the optic chiasm would have occurred in normal animals (Fig. 2). The distribution of optic nerve fibers from a transplanted eye was correlated closely with the site of entry of the optic nerve into the host brain (Fig. 1B). Transplanted optic nerves which entered the diencephalon usually gave rise to bilateral projections. Those that entered the midbrain usually gave rise to ipsilateral projections. Finally, those that entered the hindbrain projected down the spinal cord. All of these results are nearly identical to the findings for transplants to normal hosts as indicated in Figure $1 B$.

Acetylcholinesterase staining. As in Ambystoma tigrinum (Gruberg and Greenhouse, 1973), the optic neuropil of the axolotl tectum is rich in acetylcholinesterase (Fig. 5A). In eyeless axolotls, however, only a remnant of cholinesterase staining appears near the pial surface of 


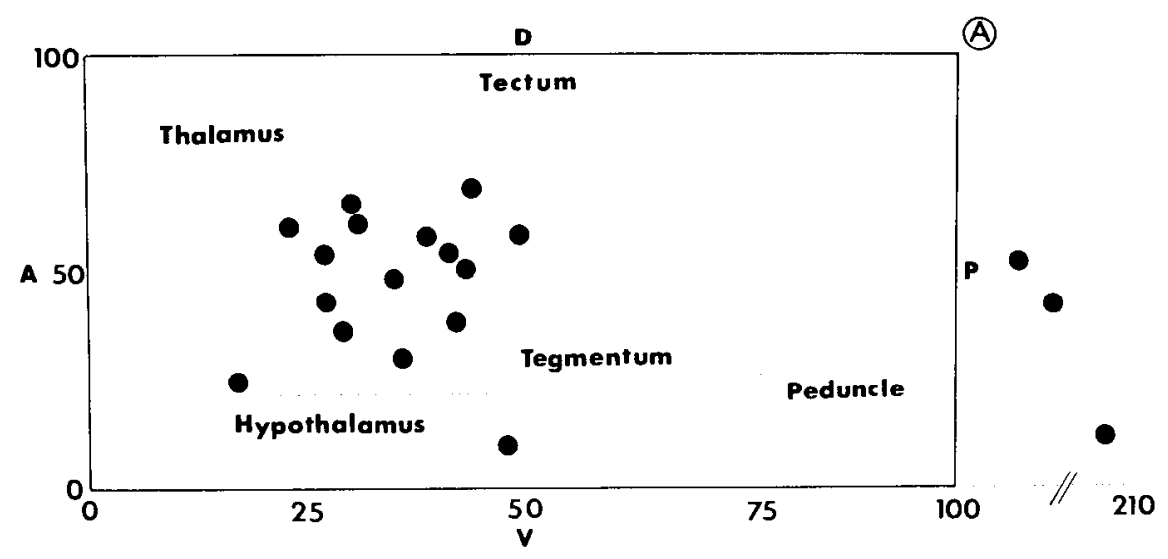

D
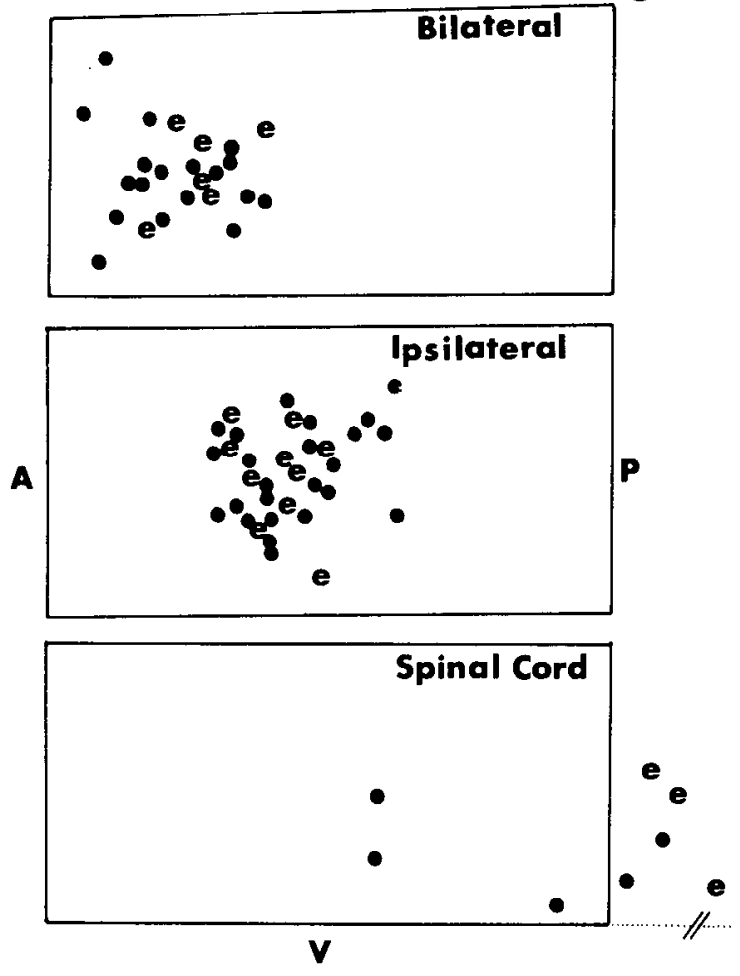

the tectum (Fig. $5 B$ ). No staining of the basal optic root was seen in the eyeless mutants although this pathway is labeled heavily in normal animals. Several other parts of the brain, such as the striatum and nucleus isthmi, and certain other fiber tracts, such as the fasciculus retroflexus, stained intensely in both the normal and mutant animals. Thus, the eyeless mutation seems to affect cholinesterase activity selectively in the areas of primary retinal projections.

Because of the histochemical difference in acetylcholinesterase activity in the visual centers of normal axolotls and eyeless mutants, it was of interest to examine mutants which had received an eye transplant. After electrophysiological experiments had confirmed that the transplanted eye had established a projection to the tectum, the animals were perfused and their brains were stained for cholinesterase. In 2 such animals, each of which showed bilateral retinal projections, dense cholinesterase activity was found bilaterally in the tecta and in
Figure 1. $A$, The entry points of transplanted optic nerves into the host (eyeless) brains. Data from all animals have been normalized, and a side view of the brain has been transformed into a rectangle for ease of analysis (cf., Fig. 6 of Harris, 1980). The anterior boundary $(A)$ marks the beginning of the diencephalon, and the posterior boundary $(P)$ marks the beginning of the cerebellum. $V$ is the ventral and $D$ is the dorsal surface of the brain. Dotted lines mark approximate boundaries of brain regions. Each solid circle represents the entry point of one transplanted nerve. To plot these, the histological section on which the nerve entered was found, and the distance between this section and the section which contained the beginning of the diencephalon was calculated as a percentage of the distance between $A$ and $P$. This gave the $A P$ coordinate. To find the $D V$ coordinate, the distance between the entry point and the ventral surface of the brain was divided by the entire dorsoventral extent of the brain in that section. $B$, Entry points of transplanted optic nerves separated according to their final destinations. The entry points into eyeless host brains are represented by $e$, and solid circles are entry points for transplants to normal hosts (data from Harris, 1980). Data were plotted as in $A$.

the basal optic roots. This pattern of labeling closely resembled that in normal animals (Fig. $5 C$ ), although the density of labeling was not measured.

Visual topography. Electrophysiological recordings from the tectal neuropil of genetically eyeless animals with a transplanted eye revealed retinotopic order in visual projections. Because eyes were transplanted to eyeless hosts in arbitrary orientations, the retinotectal maps generated by these eyes were seldom oriented normally. An example is shown in Figure 6. In this animal, successively more posterior recordings in the right tectum ipsilateral to the transplanted eye resulted in an anterior to posterior progression of visual fields. Successively more medial recordings yielded a superior to inferior progression. This map, which is abnormal in that the mediolateral axis is reversed, was the result of a left eye being transplanted to the right side of the host. Some projections, from eyes transplanted to the same side of the host from which they originated, gave rise to 


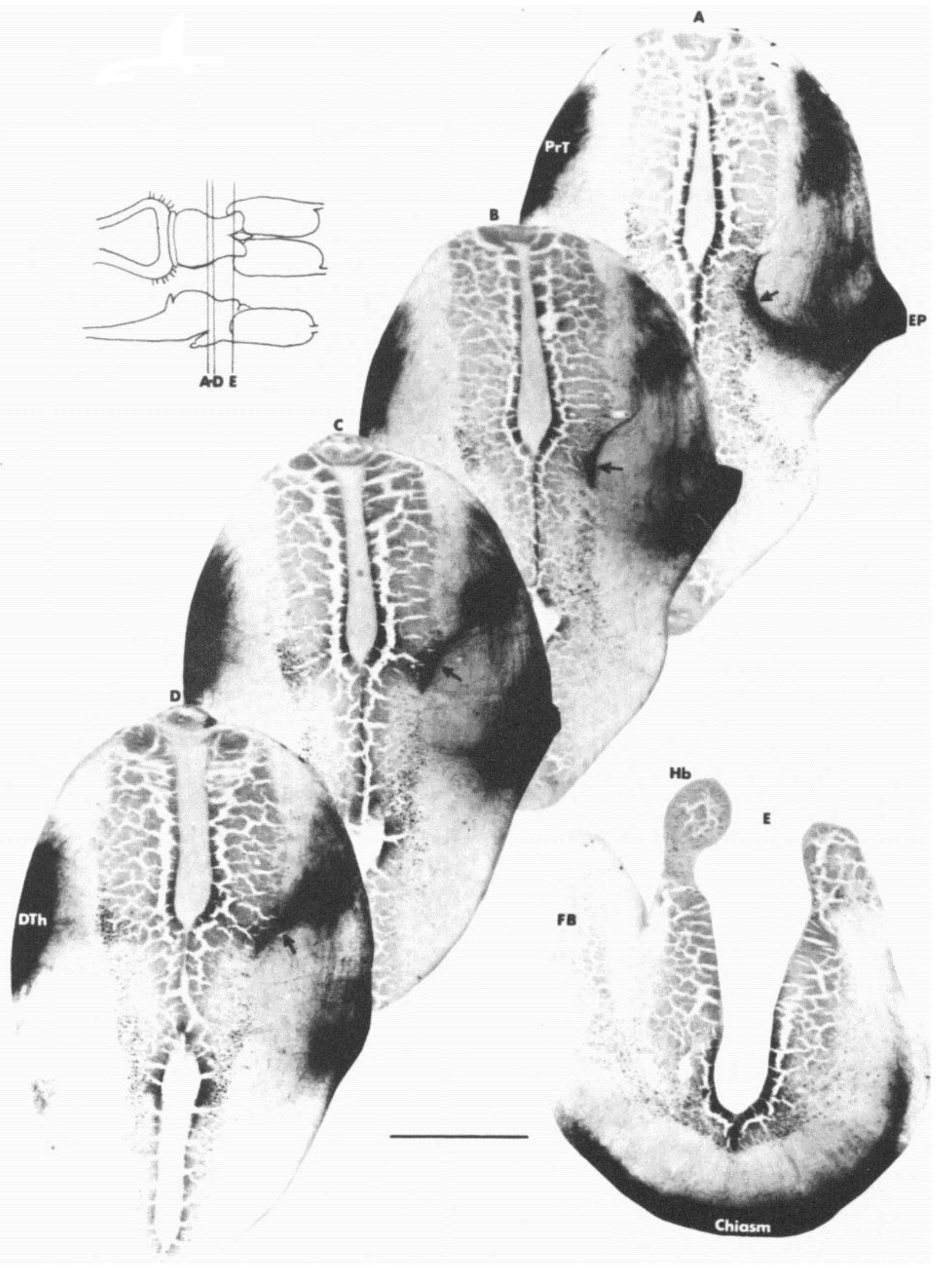

Figure 2. Example of a bilateral projection from an eye transplanted to an eyeless mutant and labeled with HRP. EP indicates the entry point in section $A$ near the beginning of the mesencephalon. $A, B, C$, and $D$ are serial sections showing the internal trajectory (arrows) of the nerve fibers as they curve toward their final targets in the dorsal thalamus (DTh) and pretectum $(\operatorname{Pr} T)$. In section $E$, the chiasm or commissure by which the labeled axons traverse from one side of the brain to the other is shown. Other abbreviations are: $H b$, habenula; $F B$, forebrain. The inset shows the approximate location of the sections. Scale bar, $500 \mu \mathrm{m}$. 

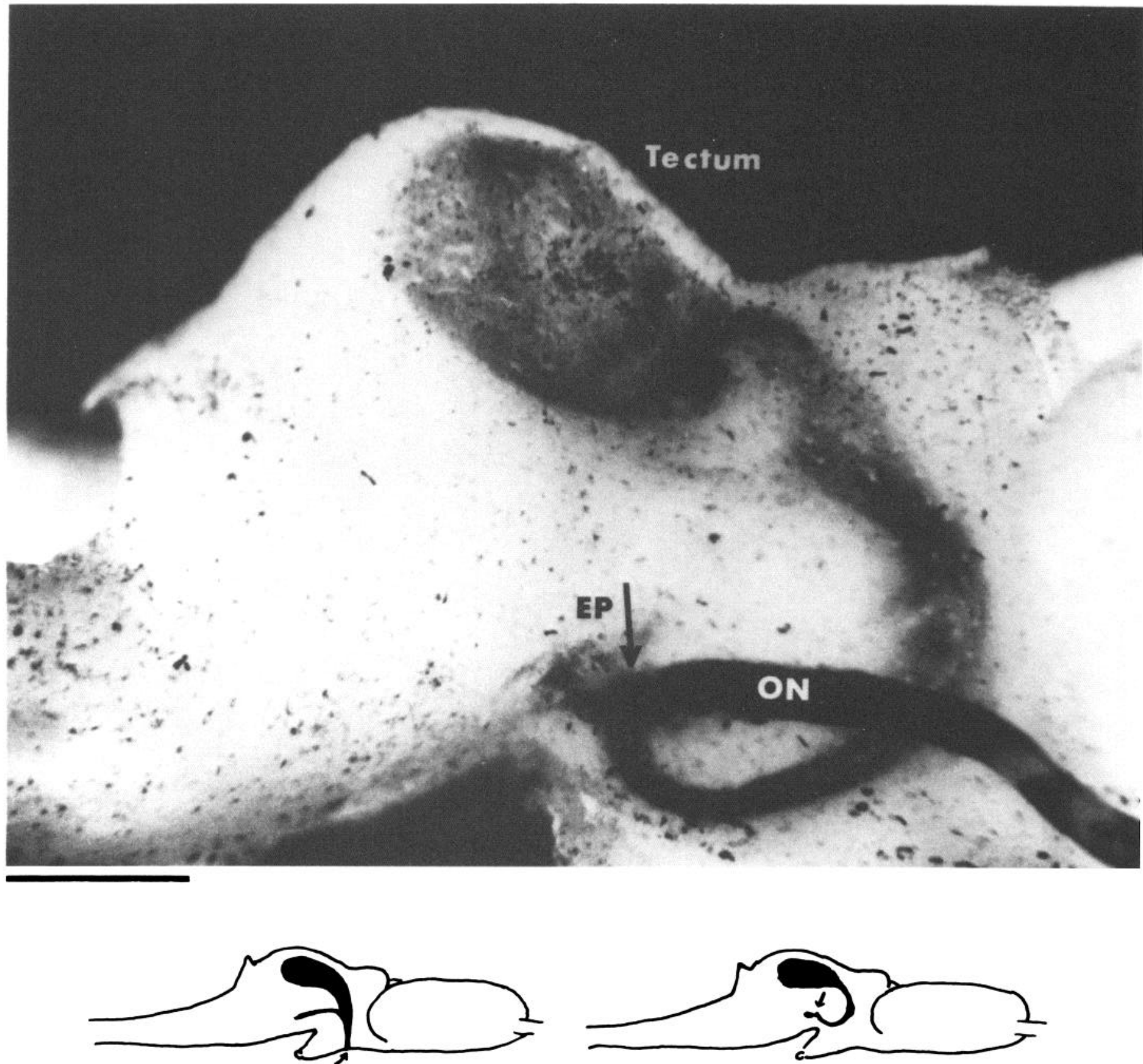

Figure 3. Example of an ipsilateral projection labeled with HRP, from an eye transplanted to an eyeless mutant. EP indicates entry point; $O N$ is the optic nerve. This is a side view of an unsectioned brain showing the entire superficial course of the transplanted fibers as they loop around toward the tectum. The small black dots over much of the surface of the brain are stained blood cells. The left inset shows, for comparison, what a normal projection from a contralateral eye would look like in a side view, and the right inset shows a drawing of the photographed transplanted projection. Scale bar, $500 \mu \mathrm{m}$.

normally oriented maps (see Table I). Of 13 visual maps studied, 4 were normally oriented, and 9 were rotated or had an axis inverted. Thus, even though the transplants were all performed before the time when the specification of retinal axes is reported to be fixed in Ambystoma (Stone, 1960), these results show that the host environment did not, in most cases, re-specify the axes of the graft. The few normally oriented maps could have been the result of transplanting eyes in normal orientations. Other recent studies also have failed to demonstrate respecification of retinal axes (Gaze et al., 1979; Sharma and Hollyfield, 1980).
Whether normally oriented or not, the retinotectal maps recorded in all of these animals were orderly (e.g., Figs. 6, 10, and 11). In each "eyeless" tectum innervated by a grafted eye, linearly arranged recording sites along the surface of the tectum yielded roughly linear progressions of receptive fields. Furthermore, penetrations perpendicular to the tectal surface in these animals yielded columns of overlapping receptive fields as in Figure 7. Thus, as in normal animals, the retinal projection to the tectum in these animals was ordered both in topography and depth.

Visual-somatosensory mismatch. In Ambystoma ti- 

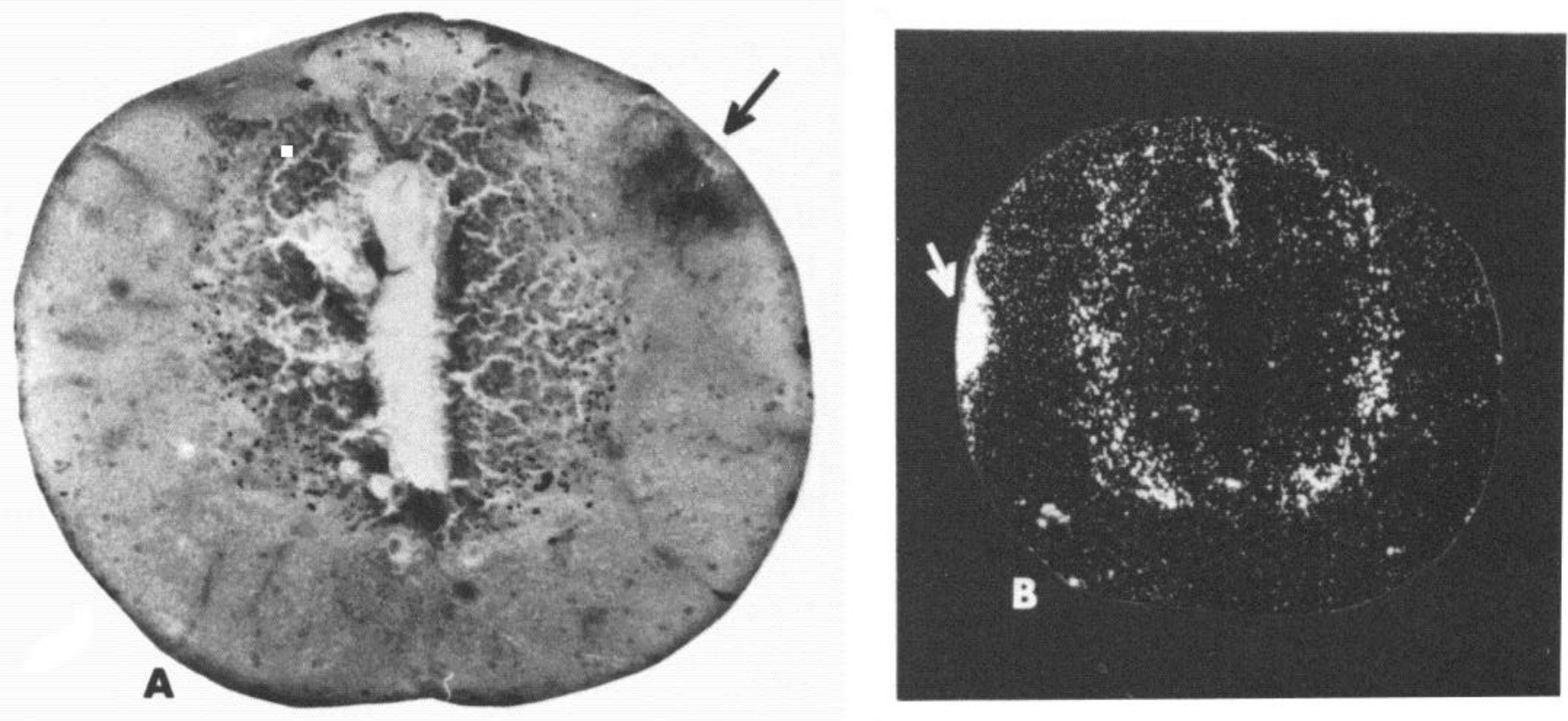

Figure 4. Two examples of spinal projections from transplanted optic nerves in eyeless mutant hosts. $A$ is a section labeled with HRP, and $B$ is a dark-field autoradiograph showing a section labeled with tritiated proline. Arrows indicate labeled fibers traveling in a dorsolateral, superficial position in the cord. Scale bar, $500 \mu \mathrm{m}$.

\section{NORMAL}

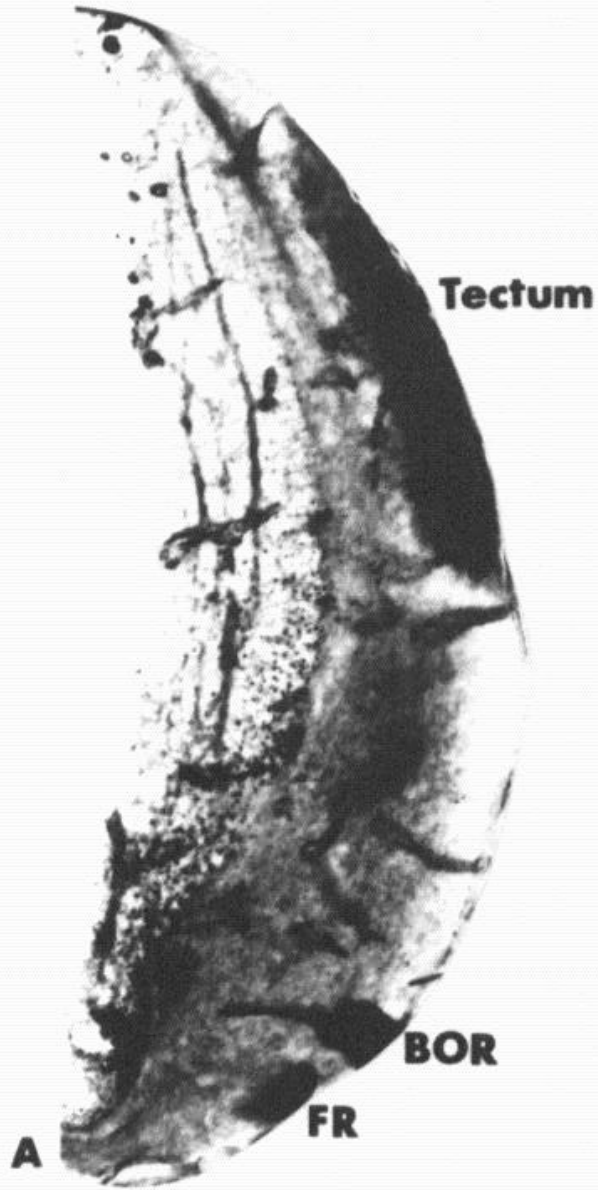

EYELESS

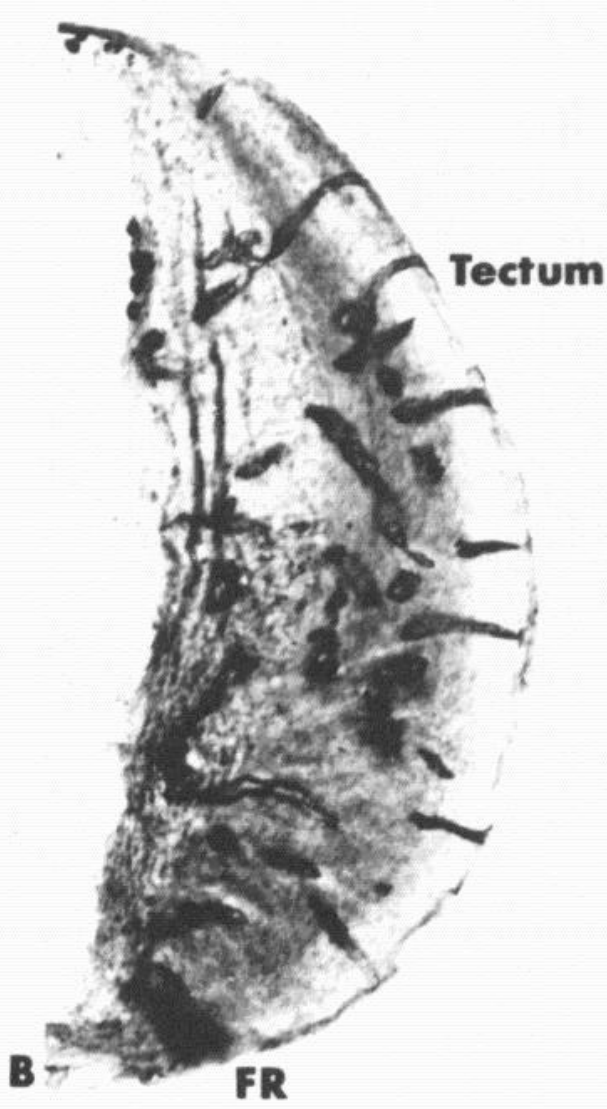

\section{EYELESS HOST}

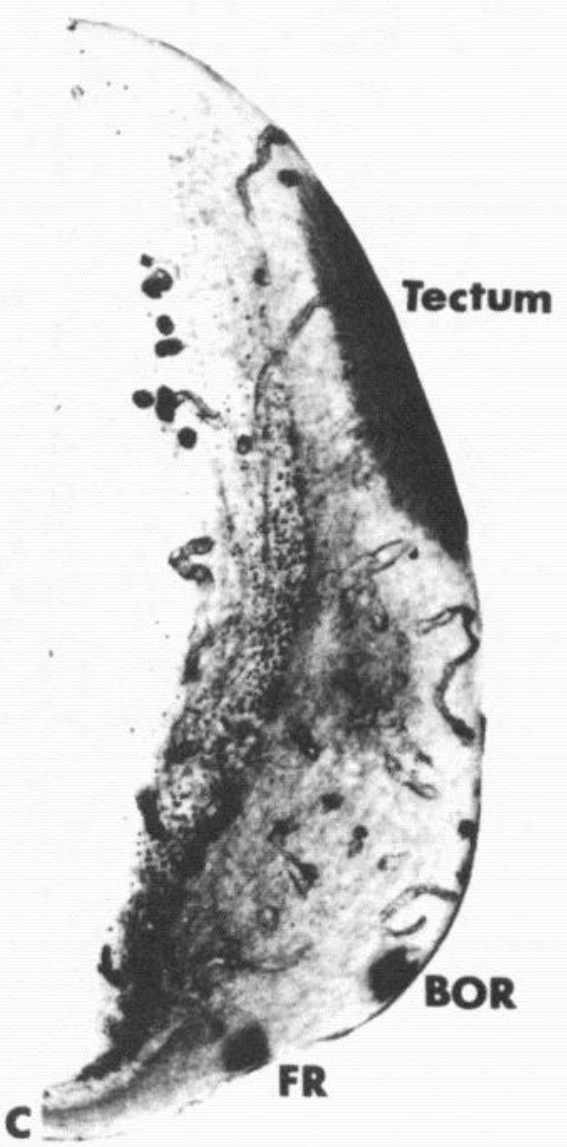

Figure 5. Acetylcholinesterase staining in a normal animal $(A)$, an eyeless mutant $(B)$, and an eyeless mutant host with an eye transplant $(C) . F R$ (the fasciculus retroflexus) is stained in all three sections while the optic tectal neuropil and basal optic root $(B O R)$ are labeled only in $A$ and $C$. Scale bar, $500 \mu \mathrm{m}$. 


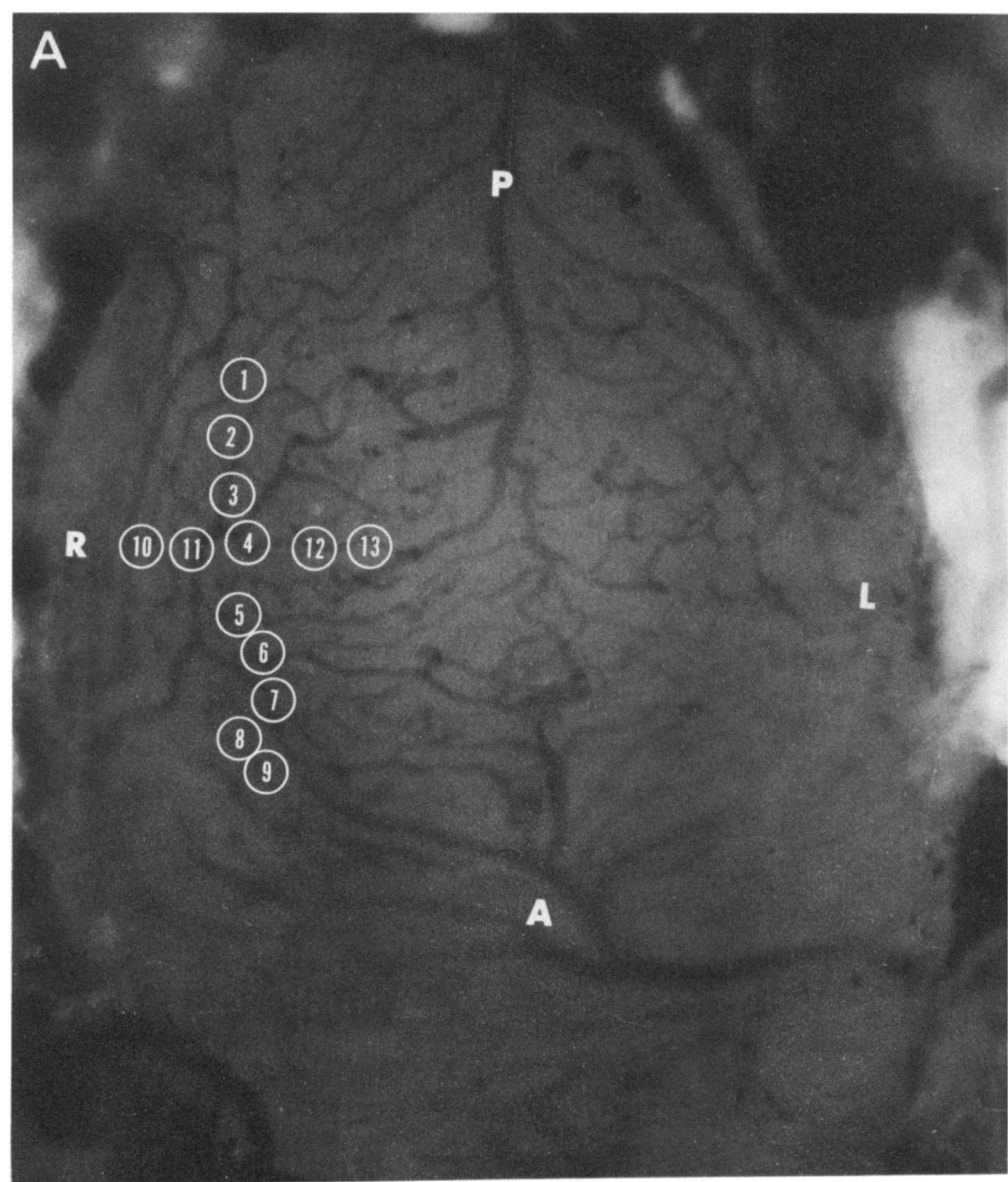

Figure 6. Visual projection of a transplanted eye to an eyeless host (see text for details). $A$ is a photograph of the tectal surface with recording sites enumerated on the right tectum. The letters, $A, P, R$, and $L$, refer to anterior, posterior, right, and left. Scale bar, $500 \mu \mathrm{m}$.

grinum, the somatosensory input to the tectum forms an orderly map, the axes of which are in register with the more dorsal visual map (Gruberg and Solish, 1978). To examine whether the same situation exists in Ambystoma mexicanum, a series of electrode penetrations perpendicular to the tectal surface and running along its rostral to caudal extent was made in 5 normal axolotls. For each penetration, the electrode was lowered in $50-\mu \mathrm{m}$ steps from the surface of the brain. In these animals, it was usual to find visually driven units at the first four or five positions in each penetration (i.e., from 0 to 200 or 250 $\mu \mathrm{m})$. The visuotopic positions of the single or multi-unit receptive fields did not vary much within a single pass, and together, they provided an average receptive field for each penetration (see Fig. 7). Somatosensory responses usually were recorded between 250 and $450 \mu \mathrm{m}$ 


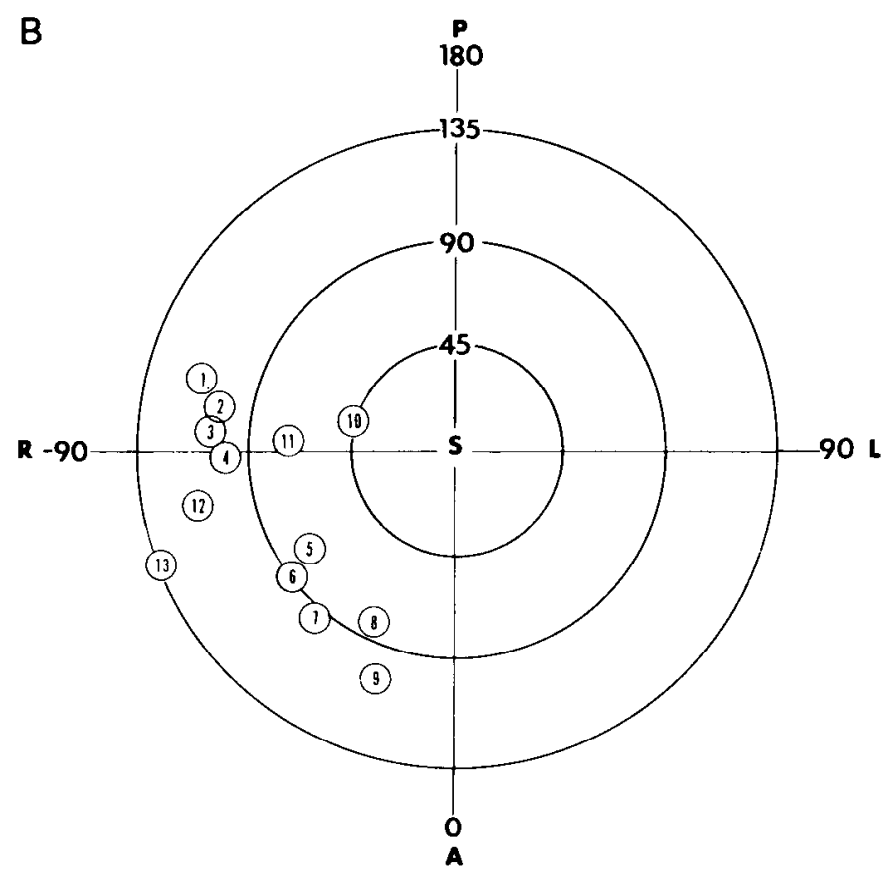

Figure 6. Continued. $B$ is the map of the visual field obtained from these recording sites. 0 is directly anterior to the animal, while 180 is directly posterior; similarly, -90 and 90 are directly right and left, respectively. Superior $(S)$ is directly overhead and 45,90 , and 135 plot decreasing altitudes in degrees, with 90 being the horizon.

below the tectal surface. Somatosensory field positions also were noted at each depth tested. As was done for visual responses, an average somatosensory receptive field was calculated for each penetration (see Fig. 7). It should be noted that the somatosensory and visual data embody nonsystematic errors. This is because (1) each animal was positioned so that the center of the back of its head was at the origin of a polar coordinate grid and (2) not all animals were identically proportioned, with some animals being thinner than others. Hence, the same angular coordinate did not correspond to precisely the same part of the body surface from animal to animal. Also, because the eyes were slightly off of the origin, a systematic distortion of the retinal coordinates was introduced into the visual data. This became larger as the interocular distance increased in bigger animals. The visual errors seemed smaller than the somatosensory ones, and neither of these factors was likely to give discrepancies greater than $10^{\circ}$.

In spite of such difficulties, a match between visual and somatosensory fields was demonstrated. An example of a normal axolotl studied in this way is shown in Figure 7 . As the recordings moved to progressively more posterior sites in the tectum, the average receptive field centers for both vision and touch were located more posteriorly. Combining the results from all 5 normal animals yielded the graph shown in Figure 8. The match is not perfect, for the somatosensory receptive fields tend to be more anterior than the visual ones, and it is unlikely that the imperfection in the match is due solely to the errors described above for the two maps do not overlap each other completely. At the caudal pole of the tectum, only somatosensory, but no visual, responses could be recorded, while at the rostral pole the reverse obtains: only visual responses were recorded. This evidence suggests that, although the axes of the two maps are in register, the precise locations of the different receptive fields for visual and somatosensory lectal units may not be the same.

To look for topography in an isolated somatosensory map, recordings were made from the tecta of 5 eyeless mutants. In these animals, as was previously reported (Gruberg and Harris, 1981), somatosensory responses were obtained from the most superficial tectal neuropil to a depth of about $300 \mu \mathrm{m}$. As was done for normal animals, receptive field positions were monitored at 50$\mu \mathrm{m}$ intervals of depth in electrode penetrations perpendicular to the tectal surface and the centers of these positions were averaged. Examples of somatosensory maps recorded from eyeless tecta are shown in Figure 9, $A$ and $B$. In all 5 animals, a clear anteroposterior shift in field position accompanied successively more caudal penetrations. Thus, the somatosensory projection to the tectum in eyeless mutants preserves its topography in spite of the absence of an overlying visual map.

The most convincing demonstration that the axes of the two maps are under independent control, however, comes from experiments in which misalignments were observed. This was done with eyeless mutants serving as hosts for rotated eye grafts. Similar experiments could be done in normal animals by enucleating one eye and rotating the other. What is critical for this experiment is that the only visual projection that the tectum ever receives is rotated. Examples of such animals, including visual and somatosensory data, are shown in Figure 10, $A$ and $B$. Altogether, 9 eyeless hosts, 7 with rotated visual projections to the tectum, were examined in this way. In 3 of the latter, the anteroposterior visual axis was rotated by approximately $180^{\circ}$. In none of the animals, however, was there an indication that the somatosensory projection was affected by the visual rotation. A summary graph for all eyeless hosts, similar to that for normal animals, is shown in Figure 11. The visual and somatosensory field positions in these animals is uncorrelated.

Pigmentation. Normal white mutants are light in color, except for their eyes, while eyeless mutants in a white background are much darker (see Epp, 1972 or Van Deusen, 1973, for pictures). It was reported previously that grafting a functional eye into an eyeless embryo sometimes resulted in normal pigmentation (Epp, 1972; Van Deusen, 1973). The pigmentation patterns in 18 of the eyeless recipients presented here were noted. All had demonstrable projections to the brain, but only 10 were normally pigmented. Surprisingly perhaps, the type of projection made by the transplant correlated with the pigmentation pattern observed (Table I). Thus, all 6 bilaterally projecting cases examined were lightly pigmented. Normal-eyed white animals and white donor animals that have a single normally projecting eye are also all lightly pigmented. However, $75 \%$ (8 of 12 ) of the ipsilaterally or spinally projecting cases were darkly pigmented. This fraction is not very different from the fraction (18 of 23) of unoperated eyeless or bilaterally enucleated white animals which are abnormally dark. 


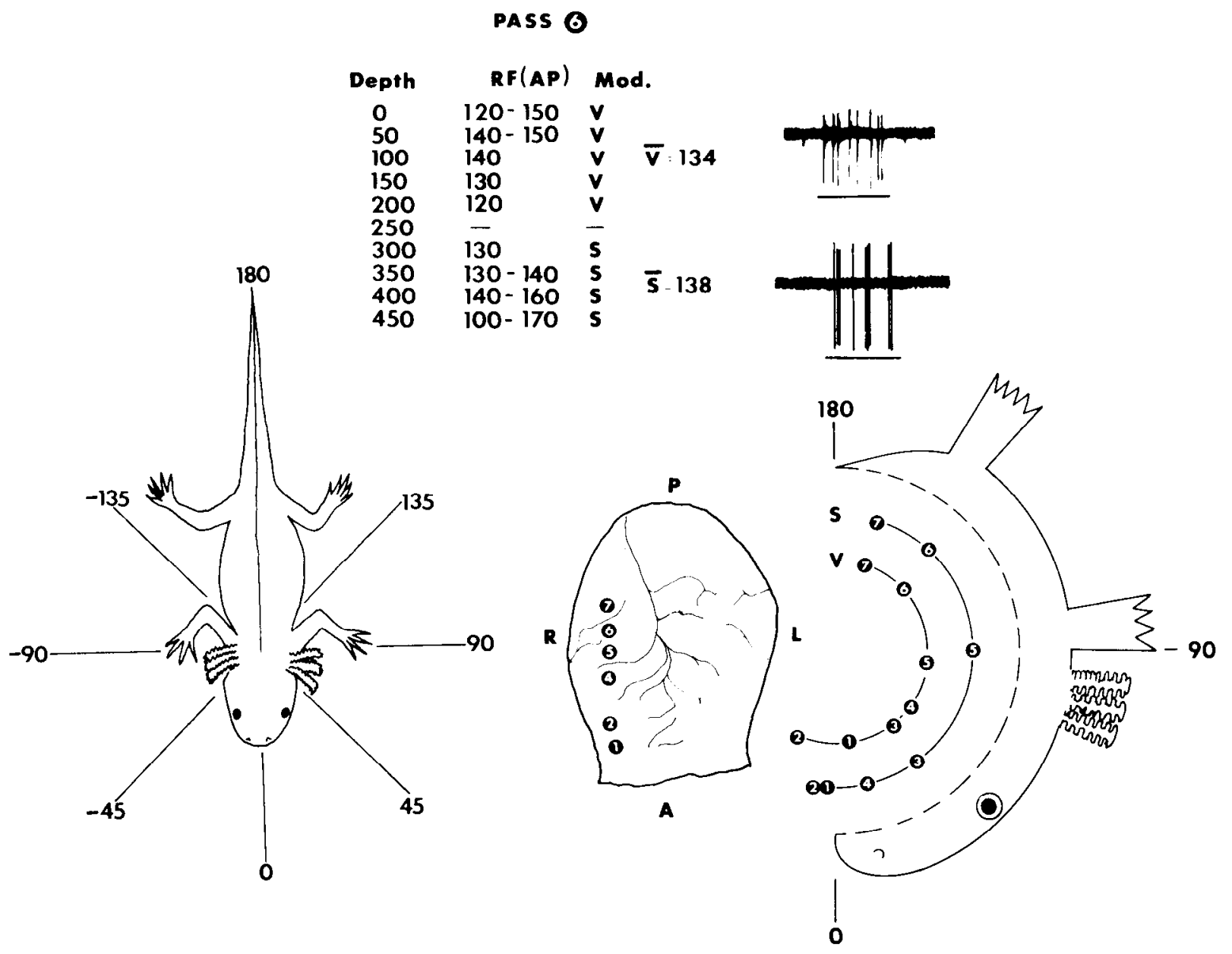

Figure 7. Visual and somatosensory data from a normal axolotl's tectum. The bottom left represents an axolotl of normal shape as it appears positioned above the polar grid. The bottom center shows a diagram of a tectal surface (redrawn from a Polaroid photograph) with the superficial electrode penetration sites labeled. $A, P, R$, and $L$ refer to anterior, posterior, right, and left. At the bottom right are plotted the visual $(V)$ and somatosensory $(S)$ average receptive field locations for each electrode pass. Only anteroposterior data are shown. The diagrammatic half-salamander shows the approximate distortion involved in plotting the somatosensory data in polar coordinates. (The dashed line is not meant to indicate the backbone.) The top left shows actual data from electrode pass 6 . Depth is given in micrometers; anteroposterior receptive fields, $R F(A P)$, are in degrees. Modality ( $M o d$.) also is indicated at each recording depth. Finally, the average field centers for each modality are calculated. The top right shows the response of a visual unit (upper) and a somatosensory unit (lower) to stimulus presentations (solid line).

\section{Discussion}

The morphological and neurochemical effects of deafferentation. The primary visual centers of eyeless animals are smaller than normal. This has been shown for embryonically enucleated fish (Schmatolla, 1972), frogs (Kollros, 1953), and chickens (Filogamo, 1950; Leghissa, 1959; Cowan et al., 1968; Kelly and Cowan, 1972); neonatally enucleated hamsters (Rhoades, 1980) and mice (Cullen and Kaiserman-Abramof, 1976; Drager, 1977); eyeless species of cave-dwelling fish (Schmatolla, 1972; Fish and Voneida, 1979); and eyeless mutants of Drosophila (Power, 1943; Meyerowitz and Kankel, 1978), axolotls (Gruberg and Harris, 1981), and mice (Cullen and Kaiserman-Abramof, 1976; Drager, 1977). The cause of the reduction in the size of the frog tectum is due at least in part to a decreased mitotic index of cells in the deprived lobes (Kollros, 1953), and this effect is due primarily, if not entirely, to glial cells (Currie and Cowan, 1974). However, no such decrease in mitosis was seen in the enucleated avian tectum (Cowan et al., 1968), and the reduction in tectal volume is due to atrophy of postsynaptic neurons (Kelly and Cowan, 1972). The lack of retinal innervation leads to a reduction of postsynaptic neuron size and a decrease in dendritic arborization in the tecta of a number of fish species (Schmatolla, 1972).

While effects on mitosis or postsynaptic neuron morphology have not been studied in the axolotl, histochemical and physiological consequences of the eyeless phenotype have been demonstrated in this animal. Formaldehyde-induced fluorescence studies of the salamander tectum show serotonergic terminals in the deep neuropil, and these terminals become abnormally superficial in eyeless mutants (Gruberg and Solish, 1978; Gruberg and Harris, 1981). Furthermore, the embryonic transplantation of an eye to these mutants results in the normal deep distribution of serotonergic fluorescence (Gruberg and Harris, 1981). A parallel arrangement of somatosensory responses has been shown physiologically in normal, mutant, and embryonically manipulated animals. In this 


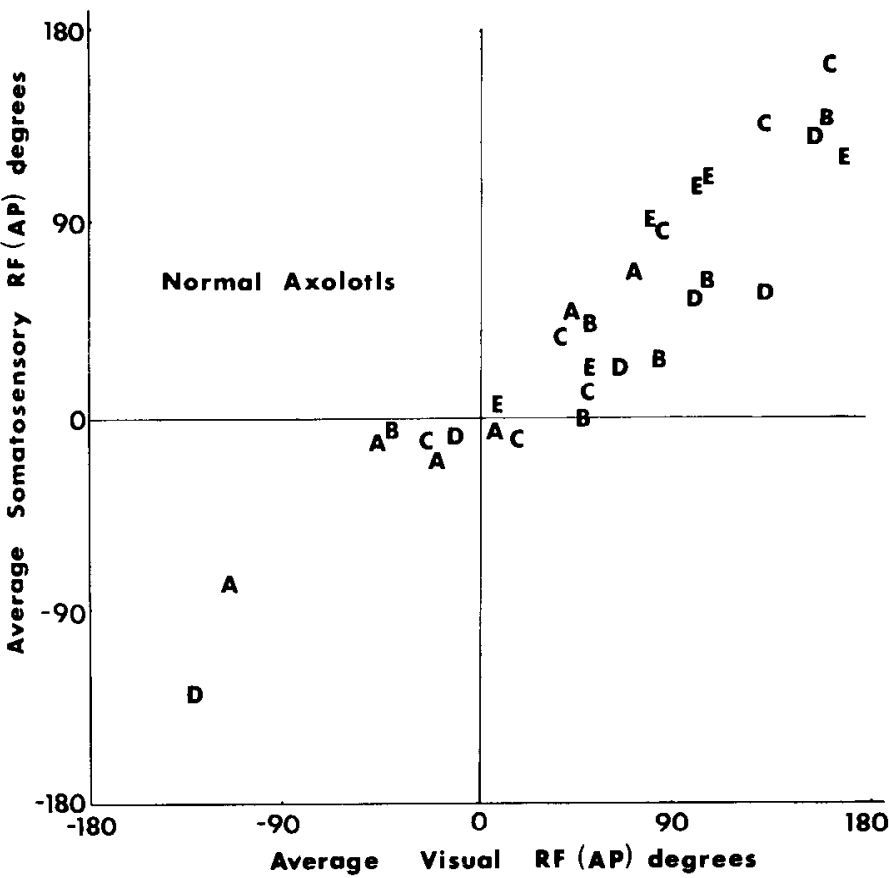

Figure 8. Correlation between visual and somatosensory receptive fields in the tecta of normal axolotls. Data are from 5 animals (distinguished by the letters $A$ to $E$ ). Each point represents the average visual and average somatosensory receptive field for a single electrode pass perpendicular to the tectal surface (see details of pass 6 in Fig. 7). The line best fitting these points by least squares analysis is $y=0.80 x+0.34$, and the correlation coefficient is $r=0.88 . R F(A P)$, anteroposterior receptive fields.

paper, it is demonstrated that the dense acetylcholinesterase staining present in the tectal optic neuropil of normal animals is a function of visual innervation. Thus, eyeless animals show greatly reduced enzyme activity in the superficial tectum, but this activity is present in mutant animals after transplantation of an eye. These observations support the notion that the retinotectal projection in cold-blooded vertebrates is at least in part cholinergic (see, e.g., Freeman, 1977; Freeman et al., 1980). The capacity to transplant an eye to the eyeless mutant and thereby restore the normal pattern of serotonergic endings and acetylcholinesterase staining in the tectum proves that these abnormalities are not a direct effect of the mutation on the postsynaptic elements but simply the result of a lack of innervation. This is supported additionally by the fact that embryonic enucleation of normal animals produces a phenocopy of the eyeless mutant in terms of the location of serotonin (Gruberg and Harris, 1981) and acetylcholinesterase (Harris, 1981).

The formation of topographic projections in the CNS. Optic fibers find their proper thalamic and midbrain targets in spite of growing into the brain at abnormal locations. Thus, to achieve these destinations, they need not follow normal pathways. Such statements were made previously because similar transplants to normal axolotl embryos and other amphibian species gave similar results (Hibbard, 1959; Sharma, 1972; Constantine-Paton and Law, 1978; Giorgi and Van der Loos, 1978; Harris, 1980). The transplantation of other sensory structures in insects also has revealed that axons can grow along anomalous pathways to reach their proper destinations (see reviews of Anderson et al., 1980; Anderson, 1981). It is possible, therefore, that afferents can seek their targets using long range, possibly chemotactic cues. The tests of this hypothesis, though, are weakened because the transplanted fibers in the above mentioned studies might have been able to find their proper targets by making contact with and then being guided by the terminals of normally growing host nerves.

Results from regeneration studies also raised the same issue, for when transected and attached to the central nervous system at ectopic locations, optic nerves are able to find their appropriate targets (Hibbard, 1967). Furthermore, regenerating nerves can find targets that are
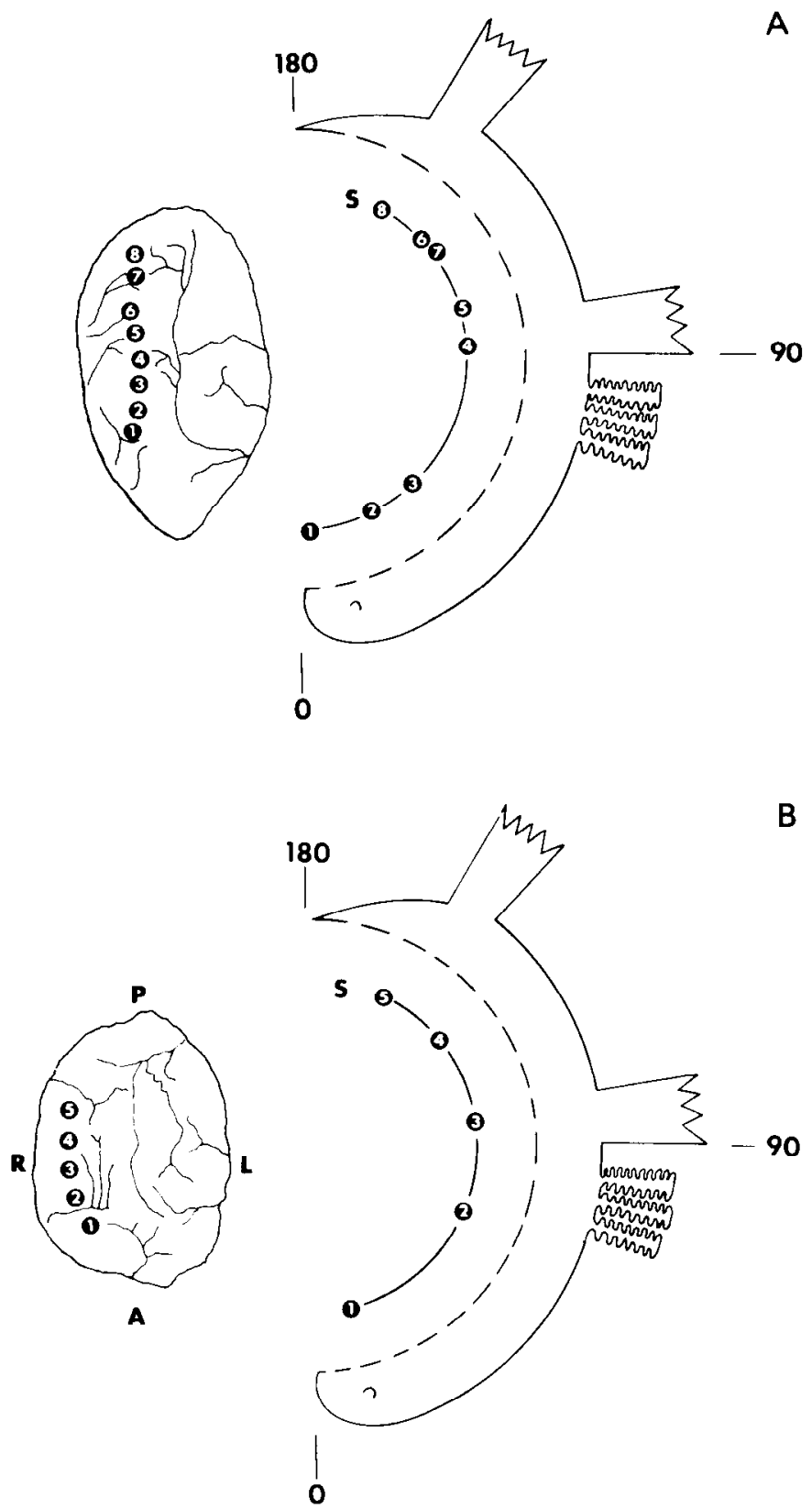

B

Figure 9. Examples of somatosensory maps recorded from the tecta of two eyeless animals $(A$ and $B$ ) showing normal topography. Conventions are as in Figure 7. 


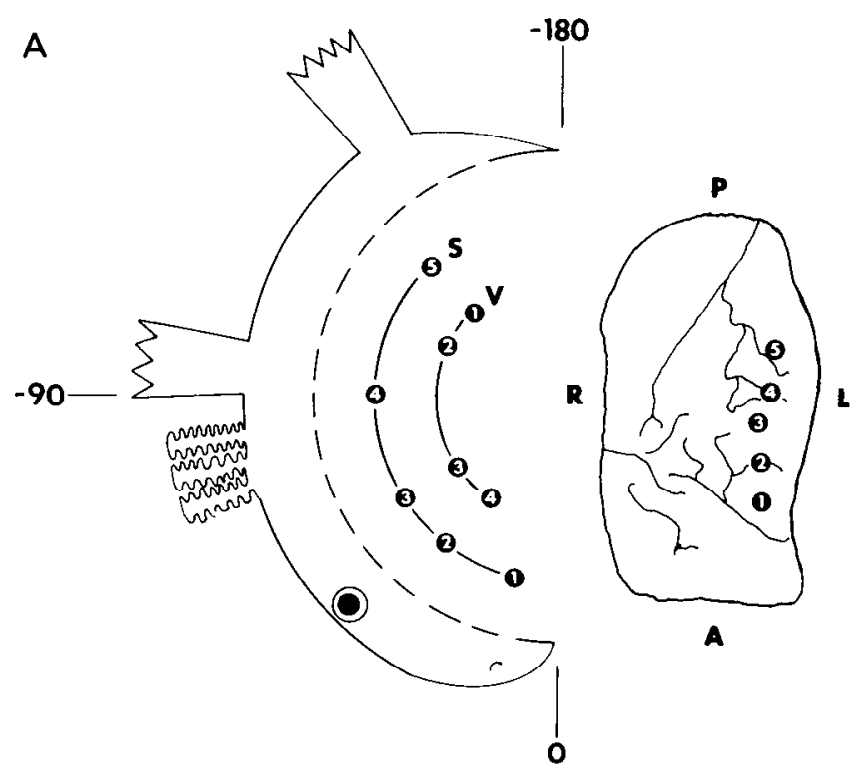

B
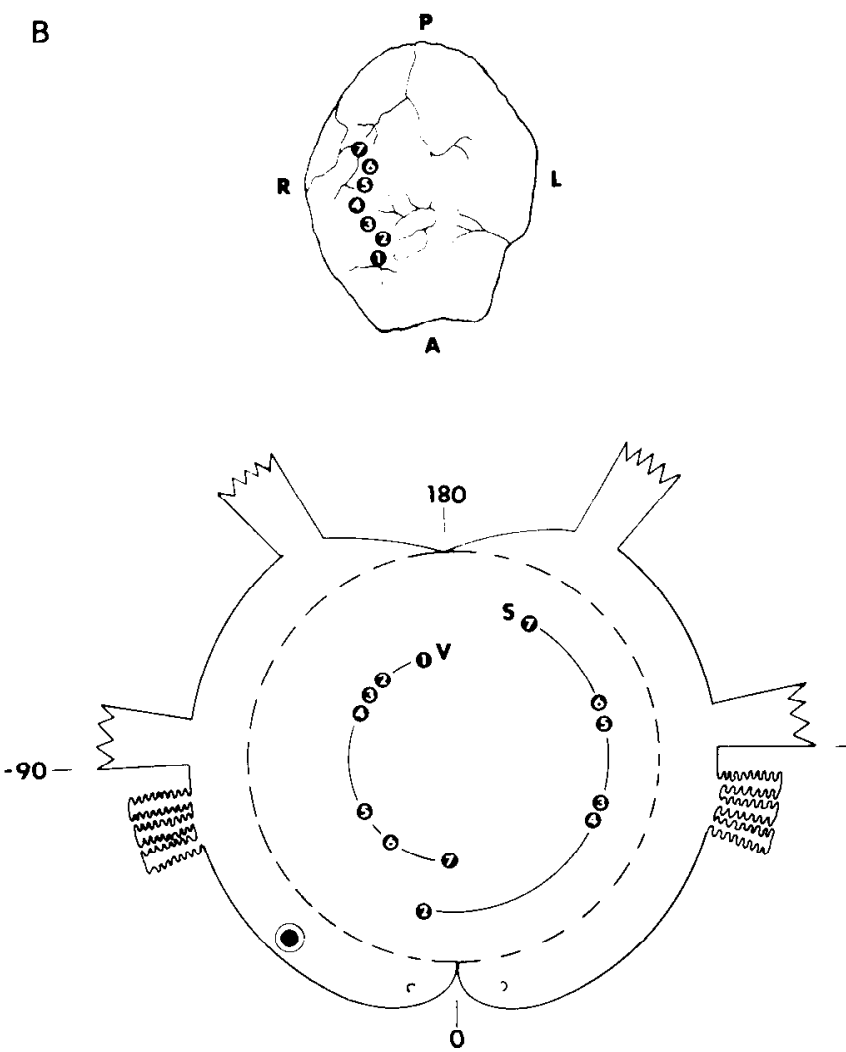

Figure 10. Examples of visual-somatosensory maps recorded from the tecta of two eyeless mutants that had received eye transplants. In $A$, the innervation was bilateral and the recordings were made from the tectum contralateral to the transplant. In $B$, the projection was ipsilateral. Conventions are as in Figure 7.

misplaced, inverted, or rotated and can do so even when they are intentionally misrouted and even though they travel in disorganized tracts (Sperry, 1945; Yoon, 1975, 1977; Fujisawa, 1981). The interpretation of these experiments is complicated by the possibility that, during development, axons must grow along fixed paths to reach their proper destinations and that, in doing so, they lay down cues, like pheromone trails, that they can follow when regenerating. These criticisms were almost completely put to rest by the experiments of Hibbard and colleagues (Hibbard and Ornberg, 1976; Schwenk and Hibbard, 1977), who showed that eyes transplanted to eyeless axolotls grow nerves which, though traveling along abnormal pathways, innervate the dorsal thalamus and tectum. It only remained to be shown that these projections to genetically eyeless hosts were visuotopic, which is one of the findings reported in this paper. Thus, we can finally say that normally organized topographic projections can be formed by fibers that travel along aberrant pathways in the central nervous system. Neither normal host projections nor persisting trails left previously by axons growing along normal routes need to exist to help the transplanted fibers find their proper targets.

Interactions between host and transplanted projections. The point at which the optic fibers enter the brain correlates with their trajectory and final destination (Constantine-Paton, 1978; Katz and Lasek, 1978; Harris, 1980). These results are similar in normal and eyeless hosts, a fact which implies that the presence or absence of host optic tracts does not influence the growth of the transplanted fibers. This is of some interest because, in other studies, there were suggestions that the opposite was true. Hibbard and Ornberg (1976) and Schwenk and Hibbard (1977) reported bilateral projections from eyes transplanted to genetically eyeless axolotls and suggested that this was due to the hosts' being eyeless. Only a few

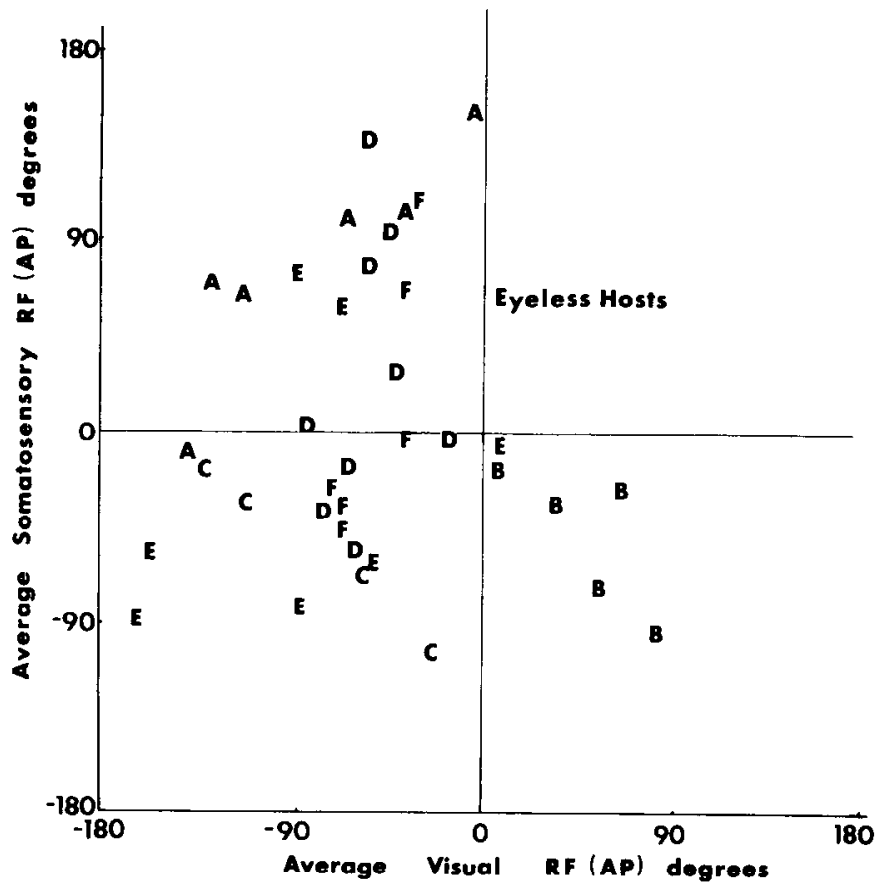

Figure 11. Correlation between visual and somatosensory receptive fields in the tecta of 6 eyeless mutants $(A$ to $F$ ) which had received eye transplants. Data are plotted as in Figure 8. The best fit line is $y=-0.08 x+5.65$, and the correlation coefficient is $r=0.004$. It might be noted, however, that, for a single animal, the points fit particular lines much better than when the points for all animals are included in the analysis. This is because the relationship of the visual to the somatosensory map is arbitrary in each of these animals, but both maps always showed specific topographies. (See text for details.) $R F(A P)$, anteroposterior receptive fields. 
animals were examined in their studies, and the results were not compared directly to data from transplants to normal animals. In the present study, care was taken to transplant eyes to positions in eyeless hosts which roughly corresponded to positions of transplanted eyes in normal hosts achieved in a previous study (Harris, 1980). This resulted in a series of entry points which gave a good overlap with those found in the previous study and, thus, many ipsilateral and spinal projections as well as bilateral projections.

Giorgi and Van der Loos (1978) found that eyes transplanted to the spinal cord of Xenopus would innervate the tectum only if the host's own eyes were enucleated. That study, however, used degeneration methods to trace fibers from the transplanted eye. Because there may have been a significant amount of natural degeneration in the CNS at the time of sacrifice and because prior enucleation of the host may have led to degeneration in the tectum, these results are difficult to interpret. The labeling of projections with HRP and radioactive proline used in the present study avoids these problems and leads to a different result, which is that the host eyes or optic tracts do not seem to influence the growth of transplanted axons. Thus, transplanted optic nerves entering the medulla of eyeless hosts do not grow to the tecta but rather grow down the spinal cord as they do in normal animals. This is very similar to recent results with homeotic mutants of Drosophila (see Palka, 1982, for review). In these studies, the metathoracic haltere is genetically transformed into a small wing and the axons of the transformed appendage are followed by cobalt staining or HRP. By introducing the wingless mutation, which often results in removal of the normal mesothoracic wings, Palka and Schubiger (1980) and Ghysen and Jansen (1980) found that absence of the normal fiber tracts had no effect on the central projections from the transformed metathoracic wing. Thus, the picture presented by invertebrates may be equally valid for vertebrates, i.e., that deafferentation has powerful effects on the development of postsynaptic neurons but no demonstrated effects on the trajectories of other centrally projecting sensory axons.

Visual-somatosensory matching. The tectum or superior colliculus of many animals is layered and multimodal, with individual layers carrying visual, somatosensory, and sometimes auditory or, in vipers, thermosensory inputs (Horn and Hill, 1966; Michael, 1971; Masland et al., 1971; Wickelgren, 1971; Stein and Arigbede, 1972; Cynader and Berman, 1972; Drager and Hubel, 1975; Hartline et al., 1978). These sensory projections to the tectum are arranged topographically, and electrode penetrations perpendicular to the tectal surface reveal that the coordinates of the separate maps are in register (Wickelgren, 1971; Gordon, 1973; Stein et al., 1976; Drager and Hubel, 1975; Tiao and Blakemore, 1976; Chalupa and Rhoades, 1977; Finlay et al., 1978) but not always in perfect register (Hartline et al., 1978). This imperfect registration, shown for normal axolotls in this paper, suggests that the maps form independently of each other (Hartline et al., 1978; Rhoades, 1980). Eyelessness in a number of vertebrate species causes the somatosensory tectal projection to become abnormally superficial (Drager, 1977; Fisher and Voneida, 1979; Rhoades, 1980). In eyeless mice and in blind fish, the somatotopic axes are arranged normally on the tectum (Drager, 1977; Fish and Voneida, 1979); this is also true in eyeless axolotls as shown in this paper. The intertectal visual projections in amphibians are in topographic register and are mediated by the isthmic nuclei (Gruberg and Udin, 1978). In embryonically enucleated animals, the isthmotectal and tectoisthmic projections also retain their proper topographic relationships (Constantine-Paton and Ferrari-Eastman, 1981; O'Leary and Cowan, 1980). Thus, normally oriented tectal maps can form in the absence of the overlying retinal projection. This, however, does not show that the maps are totally independent. For example, an experience-dependent matching has been demonstrated for the intertectal visual map in amphibians (Keating, 1974; Keating and Feldman, 1975). The transplantation of eyes to eyeless salamanders offers a powerful method for testing the possibility of functional interactions between the developing visual and somatosensory systems. In this study, eyes were grafted to eyeless axolotls in rotated orientations in order to produce a potential visual and somatosensory misalignment of maps in the tectum. The result of this experiment, that mismatched maps form and appear to be stable for at least a year, strongly suggests that the two topographic projections are formed and maintained independently of experience-related function. It remains possible, however, that a malching process aligns the maps with respect to anatomical or chemical, if not functional, criteria. Thus, for example, nasal retinal and caudal spinal inputs may make an effort to find one another in the tectum because of an anatomically regulated chemical affinity for each other.

Pigmentation. The final issue of this paper concerns the extra pigmentation that develops in eyeless axolotls which can sometimes be cured by implantation of a functional eye (Epp, 1972; Van Deusen, 1973). In this paper, it has been shown that transplanted eyes affect pigmentation only if they project bilaterally. Thus, host eyeless animals with a functional graft that projects only to the ipsilateral visual centers in the thalamus and midbrain tend to be overpigmented as do unoperated eyeless animals. The only parts of the visual pathway common to the bilateral projections of transplants and the heavily contralateral projections of normal eyes and absent in the ipsilateral projections from transplants are the components near the ventral hypothalamus and the optic chiasm (see Fig. 2E).

Optic input regulates the release of melanocyte-stimulating hormone from the pars intermedia of the pituitary via a hypothalamic inhibiting factor (Etkin, 1967). Recent results suggest that this inhibiting factor may be the neurotransmitter dopamine (Levitan, 1980; Munemura et al., 1980). Lesions of the ventral hypothalamus cause abnormal darkening in amphibians (see Etkin, 1967 and Epp, 1978, for review). The present study suggests that this area is the site of primary optic input for the control of pigmentation. This part of the hypothalamus contains the nucleus preopticus, which has many catecholaminergic cells (Sims, 1977), and a large efferent hypophyseal tract (Herrick, 1948). Therefore, it might be hypothesized that cells in this nucleus receive direct visual input, as Jakway and Riss (1972) have suggested, and that these cells project to the pars intermedia of the pituitary where 
they control, by inhibition, the release of melanocytestimulating hormone.

\section{References}

Anderson, H. (1981) Projections from sensory neurons developing at ectopic sites in insects. J. Embryol. Exp. Morphol. Suppl. 65: 209-224.

Anderson, H., J. S. Edwards, and J. Palka (1980) Developmental neurobiology of invertebrates. Annu. Rev. Neurosci. 3: $97-139$

Bordzilovskaya, N. D., and T. A. Dettlaff (1979) Table of stages of axolotl embryos and the prognostication of timing of successive developmental stages at various temperatures. Axolotl Newslett. 7: 2-22.

Brun, R. B. (1978) Experimental analysis of the eyeless mutant in the Mexican axolotl (Ambystoma mexicanum). Am. Zool. 18: 273-279.

Brun, R. B. (1980) Eye formation in the eyeless mutant axolotl Ambystoma mexicanum. Am. Zool. 20: 838.

Chalupa, L. M., and R. W. Rhoades (1977) Responses of visual, somatosensory, and auditory neurones in the golden hamster's superior colliculus. J. Physiol. (Lond.) 270: 595-626.

Constantine-Paton, M. (1978) Central projections of anuran optic nerves penetrating hindbrain or spinal cord regions of the neural tube. Brain Res. 158: 31-43.

Constantine-Paton, M., and P. Ferrari-Eastman (1981) Topographic and morphometric effects of bilateral embryonic eye removal on the optic tectum and nucleus isthmus of the leopard frog. J. Comp. Neurol. 196: 645-661.

Constantine-Paton, M., and M. I. Law (1978) Eye-specific termination bands in tecta of three-eyed frogs. Science 202: 639641.

Cowan, W. M., A. H. Martin, and E. Wenger (1968) Mitotic patterns in the optic tectum of the chick during normal development and after early removal of the optic vesicle. J. Exp. Zool. 169: 71-92.

Cullen, M. J., and I. R. Kaiserman-Abramof (1976) Cytological organization of the dorsal lateral geniculate nuclei in mutant anophthalmic and postnatally enucleated mice. J. Neurocytol. 5: 407-424.

Currie, J., and W. M. Cowan (1974) Some observations on the early development of the optic tectum in the frog (Rana pipiens), with special reference to the effects of early eye removal on mitotic activity in the larval tectum. J. Comp. Neurol. 156: 123-146.

Cynader, M., and N. Berman (1972) Receptive-field organization of the monkey superior colliculus. J. Neurophysiol. 35: 187-202.

Drager, U. C. (1977) Abnormal neural development in mammals. In Function and Formation of Neural Systems, G. S. Stent, ed., pp. 111-138, Dahlem Konferenzen, Berlin.

Drager, U. C., and D. H. Hubel (1975) Responses to visual stimulation and relation between visual, auditory, and somatosensory inputs in the mouse superior colliculus. J. Neurophysiol. 38: 690-713.

Epp, L. (1972) Development of pigmentation in the "eyeless" mutant of the Mexican axolotl, Ambystoma mexicanum, Shaw. J. Exp. Zool. 181: 169-180.

Epp, L. (1978) A review of the eyeless mutant in the Mexican axolotl. Am. Zool. 18: 267-272.

Etkin, W. (1967) Relation of the pars intermedia to the hypothalamus. In Neuroendocrinology, L. Martin and W. F. Ganong, eds., Vol. 2, pp. 261-282, Academic Press, New York.

Filogamo, G. (1950) Conseguenze della demolizione dell'abbozzo dell'occhio sulla svilluppo del lobbo ottico nel'embrione di pollo. Riv. Riol. 42: 73-79.

Finlay, B. L., S. E. Schneps, K. G. Wilson, and G. E. Schneider
(1978) Topography of visual and somatosensory projections to the superior colliculus of the golden hamster. Brain Res. 142: 223-235.

Fish, S. E., and T. J. Voneida (1979) Extravisual neurons in the optic tectum of sighted and an unsighted fish. Soc. Neurosci. Abstr. 5: 784 .

Frank, E., W. A. Harris, and M. B. Kennedy (1980) Lysophosphatidyl choline facilitates labeling of CNS projections with horseradish peroxidase. J. Neurosci. Methods 2: 183-189.

Freeman, J. A. (1977) Possible regulatory function of acetylcholine receptor in maintenance of retinotectal synapses. Nature 269: $218-222$.

Freeman, J. A., J. T. Schmidt, and R. E. Oswald (1980) Effect of $\alpha$-bungarotoxin on retinotectal synaptic transmission in the goldfish and the toad. Neuroscience 5: 929-942.

Fujisawa, H. (1981) Retinotopic analysis of fiber pathways in the regenerating retinotectal system of the adult newt $C y$. nops-Pyrrhogaster. Brain Res. 206: 27-38.

Fujisawa, H., K. Watanabe, N. Tani, and Y. Ibata (1981) Retinotopic analysis of fiber pathways in amphibians. I. The adult newt Cynops-Pyrrhogaster. Brain Res. 206: 9-20.

Gaze, R. M., J. D. Feldman, J. Cooke, and S. -H. Chung (1979) The orientation of the visual map in Xenopus: Developmental aspects. J. Embryol. Exp. Morphol. 53: 39-66.

Ghysen, A., and R. Jansen (1980) Sensory pathways in Drosophila nervous system. In Development and Neurobiology of Drosophila, O. Siddiqi, P. Babu, L. M. Hall, and J. C. Hall, eds., pp. 247-265, Plenum Press, New York.

Giorgi, P. P., and H. Van der Loos (1978) Axons from grafted eyes in Xenopus can grow into the spinal cord and reach the optic tectum. Nature 275: 746-748.

Gordon, B. (1973) Receptive fields in deep layers of cat superior colliculus. J. Neurophysiol. 36: 157-178.

Gruberg, E. R., and G. A. Greenhouse (1973) The relationship of acetylcholinesterase activity to optic fiber projections in the Tiger salamander, Ambystoma tigrinum. J. Morphol. 141: $147-154$.

Gruberg, E. R., and W. A. Harris (1981) The serotonergic somatosensory projection to the tectum of normal and cyeless salamanders. J. Morphol. 170: 55-69.

Gruberg, E. R., and S. P. Solish (1978) The relationship of a monoamine fiber system to a somatosensory tectal projection in the salamander Ambystoma tigrinum. J. Morphol. 157: $137-150$.

Gruberg, E. R., and S. B. Udin (1978) Topographic projections between the nucleus isthmi and the tectum of the frog Rana pipiens. J. Comp. Neurol. 179: 487-500.

Harris, W. A. (1980) Regions of the brain influencing the projection of developing optic tracts in the salamander. J. Comp. Neurol. 194: 319-333.

Harris, W. A. (1981) The transplantation of eyes to genetically eyeless salamanders. Soc. Neurosci. Abstr. 7: 543.

Hartline, P. H., L. Kass, and M. S. Loop (1978) Merging of modalities in the optic tectum: Infrared and visual integration in rattlesnakes. Science 199: 1225-1229.

Herrick, C. J. (1941) Development of the optic nerves of $\mathrm{Am}$. bystoma. J. Comp. Neurol. 74: 473-534.

Herrick, C. J. (1948) The Brain of the Tiger Salamander, University of Chicago Press, Chicago.

Hibbard, E. (1959) Central integration of developing nerve tracts from supernumerary grafted eyes and brain in the frog. J. Exp. Zool. 141: 323-351.

Hibbard, E. (1967) Visual recovery following regeneration in the optic nerve through the oculomotor root in Xenopus. Exp. Neurol. 19: 350-356.

Hibbard, E., and R. L. Ornberg (1976) Restoration of vision in genetically eyeless axolotls. Exp. Neurol. 50: 113-123.

Horder, T. J., and K. A. C. Martin (1978) Morphogenetics as an 
alternative to chemospecificity in the formation of nerve connections. In Cell-Cell Recognition, A. S. G. Curtis, ed., pp. 275-358, Cambridge University Press, London.

Horn, G., and R. M. Hill (1966) Responsiveness to sensory stimulation of units in the superior colliculus and subjacent tectotegmental regions of the rabbit. Exp. Neurol. 14: 199223.

Humphrey, R. R. (1969) A recently discovered mutant "eyeless" in the Mexican axolotl (Ambystoma mexicanum). Anat. Rec. 163: 306.

Jakway, J. S., and W. Riss (1972) Retinal projections in the Tiger salamander, Ambystoma tigrinum. Brain Behav. Evol. 5: 401-442.

Karnovsky, M. J., and L. Roots (1964) A "direct-coloring" thiocholine method for cholinesterases. J. Histochem. Cytochem. 12: 219-222.

Katz, M. J., and R. L. Lasek (1978) Eyes transplanted to tadpole tails send axons rostrally in two spinal cord tracts. Science 199: 204-206.

Keating, M. J. (1974) The role of visual function in the patterning of binocular visual connexions. Br. Med. Bull. 30: 145151.

Keating, M. J., and J. D. Feldman (1975) Visual deprivation and intertectal neuronal connections in Xenopus laevis. Proc. R. Soc. Lond. (Biol.) 191: 467-474.

Kelly, J. P., and W. M. Cowan (1972) Studies on the development of the chick optic tectum. III. Effects of early eye removal. Brain Res. 42: 263-288.

Kollros, J. J. (1953) The development of the optic lobes in the frog. I. The effects of unilateral enucleation in embryonic stages. J. Exp. Zool. 123: 153-187.

Leghissa, S. (1959) Studio sperimentale sul differenziamento dei neuroni del tetto ottico di Gallus. I. Esperienze di asportazione della vescicola ottica. Atti. Accad. Sci. Ist. Bologna Memorie 6: 57-75.

Lettvin, J. Y., H. R. Maturana, W. S. McCulloch, and W. H. Pitts (1959) What the frog's eye tells the frog's brain. Proc. Instn. Radio Engrs. N. Y. 47: 1940-1951.

Levitan, H. P. (1980) Monoaminergic control of MSH release in the lizard Anolis carolinensis. Gen. Comp. Endocrinol. 41: 279-286.

Malmgren, L., and Y. Olsson (1978) A sensitive method for histochemical demonstration of HRP in neurons following retrograde axonal transport. Brain Res. 14: 279-294.

Masland, R. H., K. L. Chow, and D. L. Stewart (1971) Receptive-field characteristics of superior colliculus neurons in the rabbit. J. Neurophysiol. 34: 148-156.

Meyerowitz, E. M., and D. R. Kankel (1978) A genetic analysis of the visual system in Drosophila melanogaster. Dev. Biol. 62: $112-142$

Michael, C. R. (1971) Visual response properties and functional organization of cells in the superior colliculus of the ground squirrel. Vision Res. Suppl. 3: 299-308.

Munemura, M., R. L. Eskay, and J. R. Kebabian (1980) Release of $\alpha$-melanocyte-stimulating hormone from dispersed cell of the intermediate lobe of the rat pituitary gland: Involvement of catecholamine and adenosine $3^{\prime} 5^{\prime}$-monophosphate. Endocrinology 106: 1795-1803.

O'Leary, D. D. M., and W. M. Cowan (1980) Observations on the effects of monocular and binocular eye removal on the development of the chick visual system. Soc. Neurosci. Abstr. 6: 297.

Palka, J. (1982) Genetic manipulation of sensory pathways in Drosophila. Curr. Top. Neurobiol. 5: in press.

Palka, J., and M. Schubiger (1980) Formation of central patterns by receptor cell axons in Drosophila. In Development and Neurobiology of Drosophila, O. Siddiqi, P. Babu, L. M. Hall, and J. C. Hall, eds., pp. 223-246, Plenum Press, New York.

Power, M. E. (1943) The effect of reduction in numbers of ommatidia upon the brain of Drosophila melanogaster. J. Exp. Zool. 94: 33-71.

Rhoades, R. W. (1980) Effects of neonatal enucleation on the functional organization of the superior colliculus in the golden hamster. J. Physiol. (Lond.) 301: 383-399.

Rugh, R. (1962) Experimental Embryology, Burgess Publishing Co., Minneapolis.

Schmatolla, E. (1972) Dependence of tectal neuron differentiation on optic innervation in teleost fish. J. Embryol. Exp. Morphol. 27: 555-576.

Schwenk, G., and E. Hibbard (1977) An autoradiographic study of optic fiber projections from eye grafts in eyeless mutant axolotls. Exp. Neurol. 55: 498-503.

Sharma, S. C. (1972) Retinotectal connections of a heterotopic eye. Nature New Biol. 238: 286-287.

Sharma, S. C., and J. G. Hollyfield (1980) Specification of retinotectal connexions during development of the toad Xenopus laevis. J. Embryol. Exp. Morphol. 55: 77-92.

Sims, T. J. (1977) The development of monoamine-containing neurons in the brain and spinal cord of the salamander, Ambystoma mexicanum. J. Comp. Neurol. 173: 319-336.

Sperry, R. W. (1945) Restoration of vision after uncrossing of optic nerves and after contralateral transposition of the eye. J. Neurophysiol. 8: 15-28.

Stein, B. E., and M. O. Arigbede (1972) Unimodal and multimodal response properties of neurons in the cat's superior colliculus. Exp. Neurol. 36: 179-196.

Stein, B. E., B. Magalhaes-Castro, and L. Kruger (1976) Relationship between visual and tactile representations in the cat superior colliculus. J. Neurophysiol. 39: 401-419.

Stone, L. S. (1960) Polarization of the retina and development of vision. J. Exp. Zool. 145: 85-93.

Tiao, Y. -C., and C. Blakemore (1976) Functional organization in the superior colliculus of the golden hamster. J. Comp Neurol. 168: 483-503.

Ulshafer, R. J., and E. Hibbard (1979) An SEM and TEM study of suppression of eye development in eyeless mutant axolotls. Anat. Embryol. (Berl.) 156: 29-35.

Van Deusen, E. (1973) Experimental studies on a mutant gene (e) preventing the differentiation of eye and normal hypothalamus primordia in the axolotl. Dev. Biol. 34: 135-158.

Wickelgren, B. G. (1971) Superior colliculus: Some receptive field properties of bimodally responsive cells. Science 173: 69-72.

Yoon, M. G. (1975) Readjustment of retinotectal projection following reimplantation of a rotated or inverted tectal tissue in adult goldfish. J. Physiol. (Lond.) 252: 137-158.

Yoon, M. G. (1977) Retinotectal projection after translocation of two tectal grafts within the same optic tectum in goldfish. Soc. Neurosci. Abstr. 3: 385. 